$3(3.3 \%)$ patients. One infant who presented at day 71 of life was identified to have biliary atresia, one infant had a urinary tract infection, and one infant had a positive reducing sugar and confirmed to be lactose intolerant. Four patients had $\mathrm{ABO}$ incompatibility but were otherwise well.

Conclusion In our study, we found only one baby with conjugated hyperbilirubinaemia who presented late. The remainder of the babies investigated for prolonged jaundice were benign. Majority of the infants (72\%) were breastfed, which is a wellrecognised cause for prolonged jaundice. As such, the authors propose that in well babies with pigmented stools, performing the prolonged jaundice screen at 21 rather than 14 days could reduce the burden of carrying out unnecessary tests without causing significant detriment to these patients.

\section{PS-058 KEROSENE POISONING IN MALIAN CHILDREN: A 11-YEAR RETROSPECTIVE STUDY}

${ }^{1} \mathrm{~T}$ Diallo, ${ }^{2} \mathrm{H}$ Hami, ${ }^{1} \mathrm{~A}$ Maïga, ${ }^{3} \mathrm{H}$ Sangho, ${ }^{2} \mathrm{~A}$ Mokhtari, ${ }^{4} \mathrm{R}$ Soulaymani-Bencheikh, ${ }^{2}$ A Soulaymani. ${ }^{1}$ Faculty of Medicine Pharmacy and Odonto-Stomatology, University of Bamako, Bamako, Mali; ' Laboratory of Genetics and Biometry, Faculty of Science Ibn Tofail University, Kenitra, Morocco; ${ }^{3}$ Center for Research, Studies and Documentation on Child Survival, Bamako, Mali; ${ }^{4}$ Moroccan Poison Control Center, Rabat, Morocco

\subsection{6/archdischild-2014-307384.356}

Background and aims Acute poisoning is a major preventable public health problem among children in developing countries. The aim of this study is to determine the epidemiological features of kerosene poisoning in Malian children.

Methods This is a descriptive retrospective study of kerosene poisoning in children under the age of 6 years, recorded between 2000 and 2010 in the medical records and the consultation registers at 15 hospitals in Mali.

Results There were 98 children poisoned by kerosene in Mali, accounting for $11.1 \%$ of all poisoning cases reported in children under the age of 6 years during the period of study. The average age of the patients was $1.8 \pm 1.1$ years. More than half of the cases $(57.1 \%)$ were males with a male-female ratio of 1.3 . The median delay in presentation to hospital was $3.6 \mathrm{~h}$. According to the results, the poisoning symptoms were varied, depending on the ingested quantity and the delay before treatment. The average length of stay in hospital was $34 \mathrm{~h}$, with a range of $1 \mathrm{~h}$ to 7 days. Among the cases for whom the outcome was known, 5 of them died. For other cases, the outcome was favourable with or without sequelae.

Conclusions The real number of kerosene poisoning in children is probably underestimated, because of the undiagnosed and unreported cases.

\section{\begin{tabular}{l|l} 
PS-059 WITHDRAWN & WW
\end{tabular}}

\section{PS-060 MODULATION OF L-ARGININE CHANGES NEONATAL T-CELL POLARISATION AND REGULATION}

Yu Hong-Ren, Kuo Ho-Chang, Tain You-Lin. Pediatrics, Chang Gung Memorial HospitalKaohsiung Medical Center, Kaohsiung, Taiwan

\subsection{6/archdischild-2014-307384.357}

Background and aims A growing number of diseases (trauma, certain cancer, and certain infection) in humans appear to be associated with L-arginine deficiency. In condition of L-arginine depletion, T-cell proliferation is impaired. In mice model, certain Th2 conditions were shown to activate arginase and lead to Larginine depletion. However, the modulation effects of L-arginine towards T-cells immune polarisation and regulation are not understood.

Methods To investigate the different modulation effects of Larginine on neonatal and adult lymphocyte polarisation, the cytokines produced by cord blood mononuclear cells (CBMC) and adult peripheral blood mononuclear cells (PBMC) at indicated L-arginine were determined.

Results CBMC produced less Th1 but higher Th2 cytokines than PBMC. Both adult and neonate $\mathrm{T}$ cells cannot produce IFN- $\gamma$ efficiently in the absence of L-arginine. But high IL-4 and
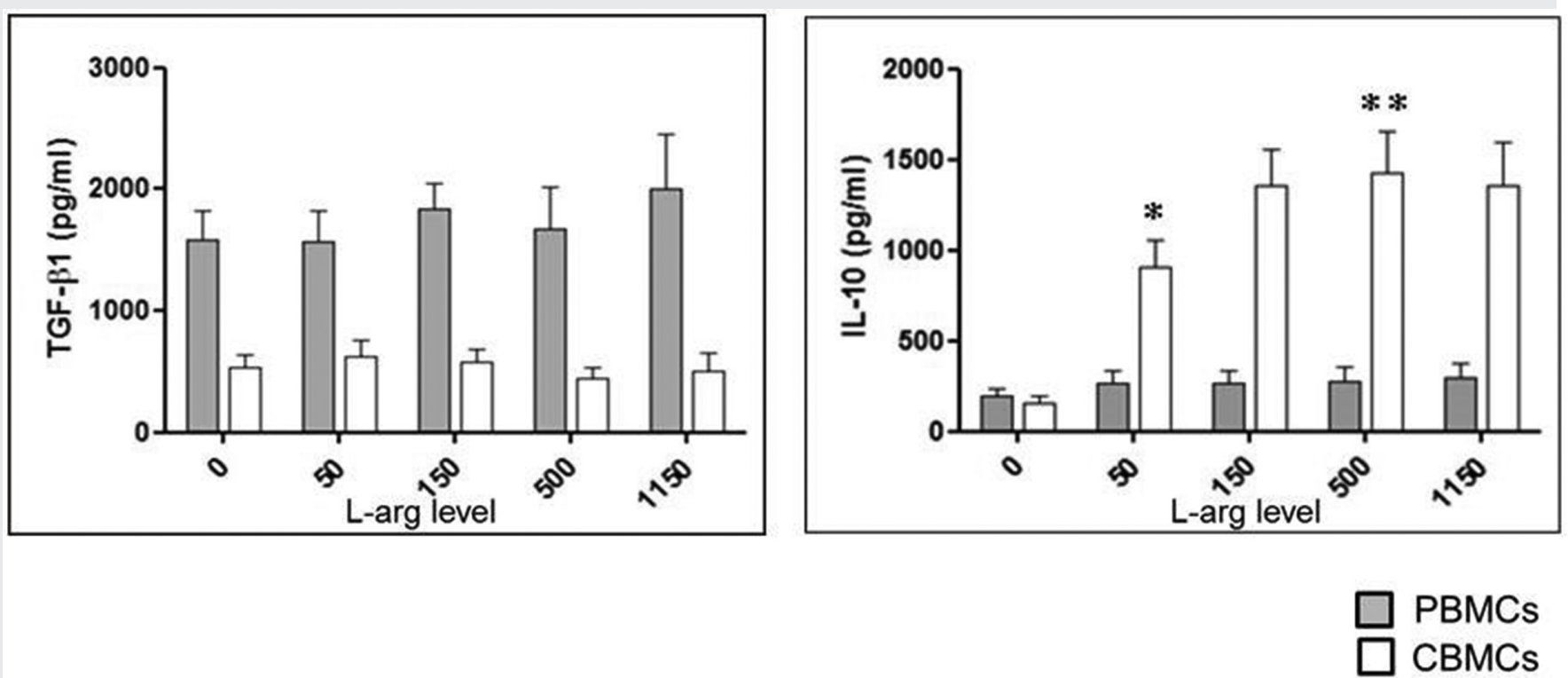